\title{
Multiple Grammars, Feature-Attraction, Pied-Piping, and the Question: Is AGR inside TP?
}

\author{
Tom Roeper
}

University of Massachusetts February 2003

\subsection{Introduction:}

Linguistic Theory always contained a promise: the explanation of language acquisition. ${ }^{1}$ This promise has two natural dimensions: one profound dimension is the providing of insight into how children choose one grammar from among the set of possible grammars. Another dimension is equally important: the fundamental operations of grammar should be transparent and therefore find unique support in acquisition. ${ }^{2}$ A typical case is the concept of transformation: the perennial appearance of copying ("Can I can come") supports the view that a transformation should be formulated as: copy then delete. This insight is maintained under the formulation of movement as Agree, Mark, Delete recently advocated by Chomsky (2000). In general, where adult grammars provide a conglomerate output, acquisition predicts that microscopic operations could appear as independent steps.

In what follows we will develop an acquisition-oriented perspective on the question of the Universal Base Hypothesis and on the constraints governing Feature-checking. It then entails:

A) an additional metric of economy, and

B) an argument in behalf of a single Tns/Agr node.

Finally we argue that Default choices in early child grammars support a theory of Multiple Grammars, where each module involves a different economy metric.

\subsection{Universal Base and Feature-checking Acquisition}

Two questions lie at the heart of much recent theory:

1a) How much of the base structure is Universal and how much variation is there?

\footnotetext{
${ }^{1}$ Thanks to audiences in Purdue, Michigan State University, Leiden, the Summer school in Düsseldorf and to conversations with Elena Benedicto, Kyle Johnson, Larry Leonard, Alan Munn, Natascha Müller, Uli Sauerland, Christina Schmidt and for comments from two anonymous reviewers and Natascha Müller. I am particularly indebted to stimulating suggestions from Gereon Müller (see Müller (2002).

${ }^{2}$ Work by Lebeaux (2000), Roeper (1996), Powers (1995), Hoekstra and Jordens (1992), Drenhaus (2001),Schützenberger and Penner (1995) is directly pertinent to these questions, and many other papers are indirectly relevant.

${ }^{3}$ See Roeper (1999), Yang (2000), Kroch and Taylor (1997), Müller and Hulk (2001), Tracey (1991), Satterfield (2000).
} 
b) How does Feature-checking work and how does it accommodate the fact that whole phrases and not just Features undergo movement? (Pied-piping).

At one extreme is the view that there is a fixed universal base: all nodes are the same in all grammars. At the other extreme is the view that a large variety ${ }^{4}$ of nodes are possible. Children might then have radically underspecified nodes in the process of determining the Feature content of nodes in their grammar. ${ }^{5}$

\subsection{Separate Nodes or a Single Node}

Two claims about the fundamental nature of tree-structure have recently been articulated. Chomsky (2000) has argued that there is only one TP node and Agreement features are located within it. Chomsky motivates this claim on abstract grounds: all nodes should represent interpretable features. If AGR is an uninterepretable feature, then it should not be an independent node. Guasti and Rizzi (2001) have argued for the Split-IP perspective which claims that AGR and Tense are separate nodes.

Let us take a close look at the mechanisms involved. Under Chomsky (2000). the lexical item Probes for the features which will satisfy it in the TensePhrase (see also Bobalijk (1995)). The $-\mathrm{s}$ affix on a word like play carries both the AGR and Tense features. It moves from the VP up to the TP which has empty Feature positions that must be assigned a value and then delete ${ }^{6}$ :

\footnotetext{
${ }^{4}$ There is a substantial tradition of work in Underspecification, from Roeper (1992, 1996), (especially) Hyams (1996) and recently Schütze (2002). We take the extreme form to be a node characterized by just a few Features, rather than an underspecified label. In principle there might be a difference: a CP node with only certain features, or just arguing that the node has [+tense][+complement].

${ }^{5}$ In between, lie many tantalizing possibilities. Hollebrandse and Roeper (1997).have argued that the Split-IP hypothesis reflects an acquisition operation. (See also Perez,. Munn, and Schmidt (in preparation) for further arguments about node-splitting in acquisition ). Children maximize the Features under a projection and then split them if evidence forces them to. Others have argued that children's first projections are radically underspecified. Possibly, some nodes are initially underspecified and other others are overspecified. The challenge for every technical proposal is to find empirical evidence that chooses between them.

${ }^{6}$ Adger (pc) argues for a different technology where the affix is not generated in the lower position. This is a possible option does not change the core argument. that the TP/AGRP are not split.
} 
2)

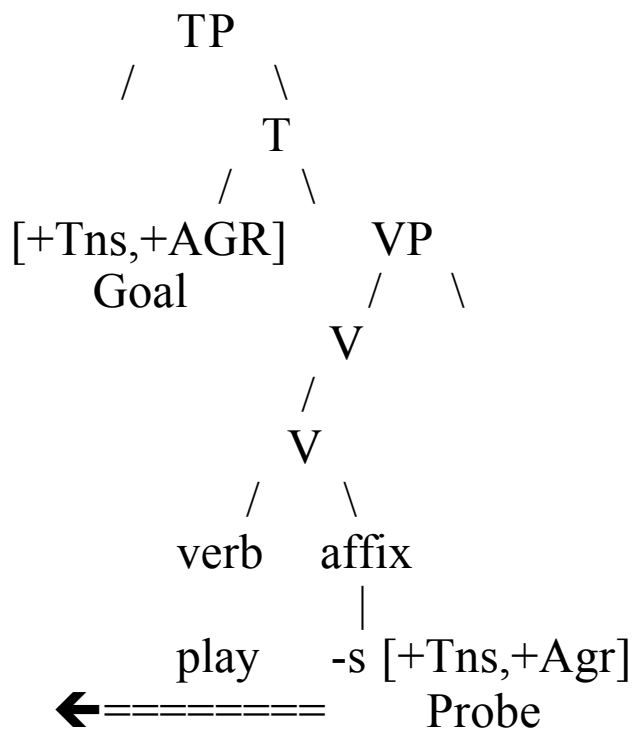

Guasti/Rizzi (2001) propose an alternative in which each feature is captured by a separate node and the derivation checks them off independently.

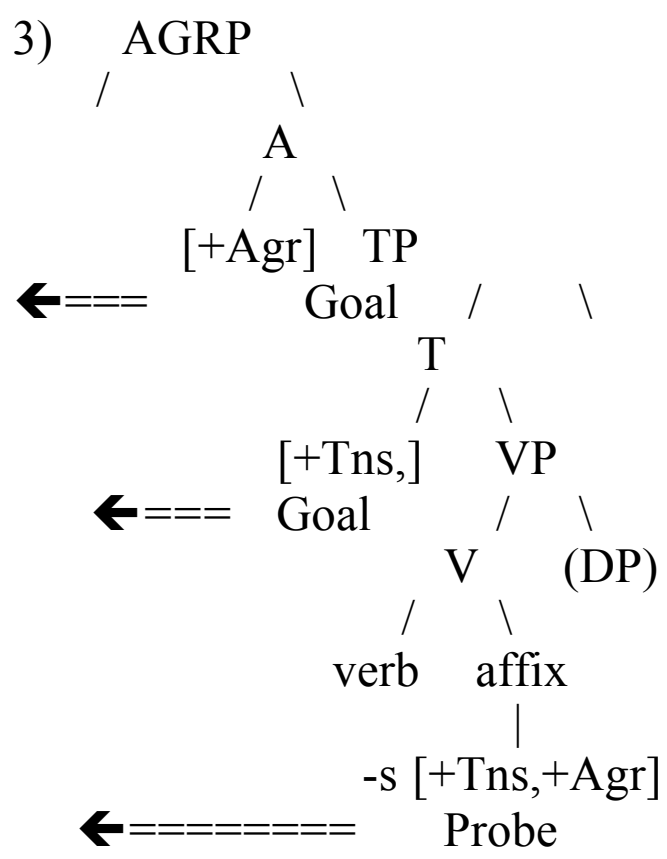

As we shall show, there is empirical evidence on behalf of both of these perspectives. It is a sign that theories are appropriate when subtle data is relevant to subtly different formulations.

In order to make the argument, however, we must first refine the concept of 
Feature-checking itself.

\subsection{Seek Sublabel/Path Economy}

One of the surprising mysteries of grammar is the existence of Pied-Piping, the fact that the grammar machine may move more than is initially needed:

4)a. a picture of whom did he see

b. who did he see a picture of.

Why does the whole phrase "a picture of whom" move to the front when, as (4b) shows, it would be enough to move just "who"? We will suggest an answer below, following the analysis of Hollebrandse and Roeper (1997) but since both are grammatical, we must allow Feature-checking to operate on both of them.

Nevertheless most speakers prefer (4b) and that preference deserves some attention. Note that, in principle, the same distinction, less contrastive intuitively, is found in cases like:

4c. who did you talk to

d. to whom did you talk.

How does Feature-checking find the crucial, but buried [+wh] in cases like $(4 a, d)$ ? To find the Feature, it is is necessary to pass down through the moved DP structure in cases like (4a) in order to find the [+wh] in the object of the PP (picture of whom). Checking must move through DP, D, NP, PP, NP, N to find whom. Chomsky (1995) labels this process Seek Sublabel, but he does not discuss the computational character of the operation.

\section{Seek Sublabel:}

"we have to have an elementary way to determine the features of alpha and $\mathrm{K}$ that enter into this checking relation no matter how deeply embedded these are in alpha and $\mathrm{K}^{\prime \prime}$

"F enters into a checking relation with a sublabel of $\mathrm{K}$ as a result of the operation (move)" (1995: 268) phrase:

Thus CP[+wh] must connect with whom [+wh] within the Pied-piped 


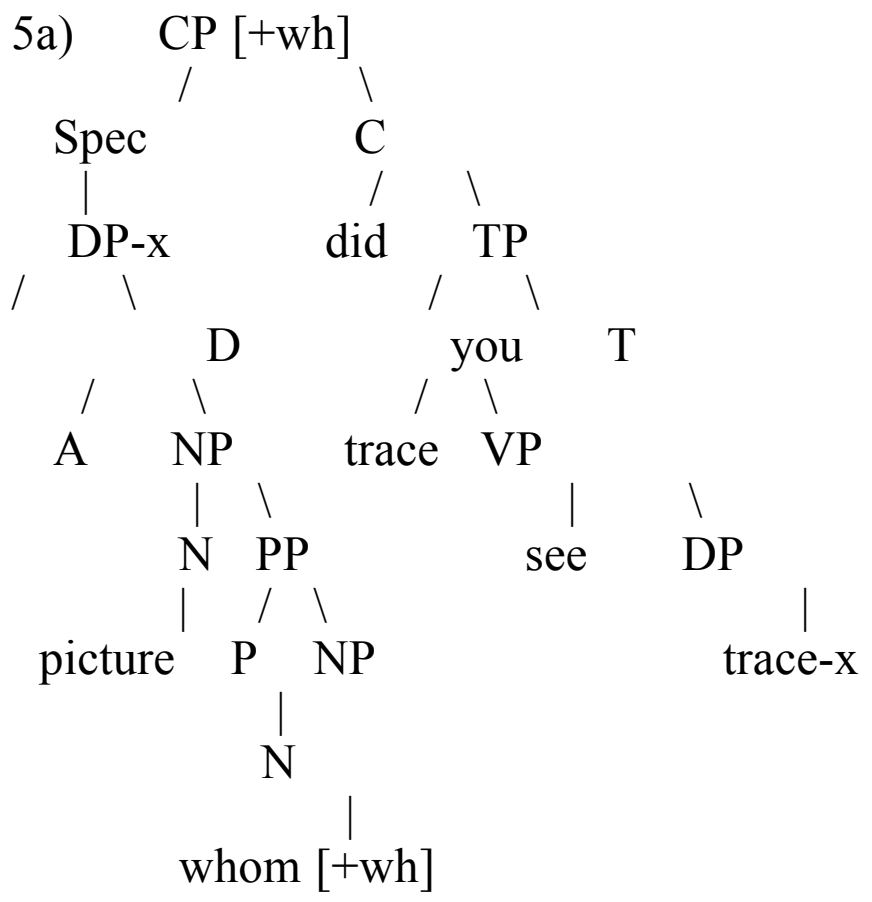

The alternate form requires Minimal Seek Sublabel because [+wh] is immediately dominated by Spec-CP. In addition, the minimal tree allows the $[+w h]$ feature to Immediately $\mathrm{C}$-command the verbal chain $[\mathrm{C}, \mathrm{TP}, \mathrm{VP}, \mathrm{t}]$ :

4b) who did you see a picture of $=>$ Short Seek Sublabel, Immediate Feature Command 
6)

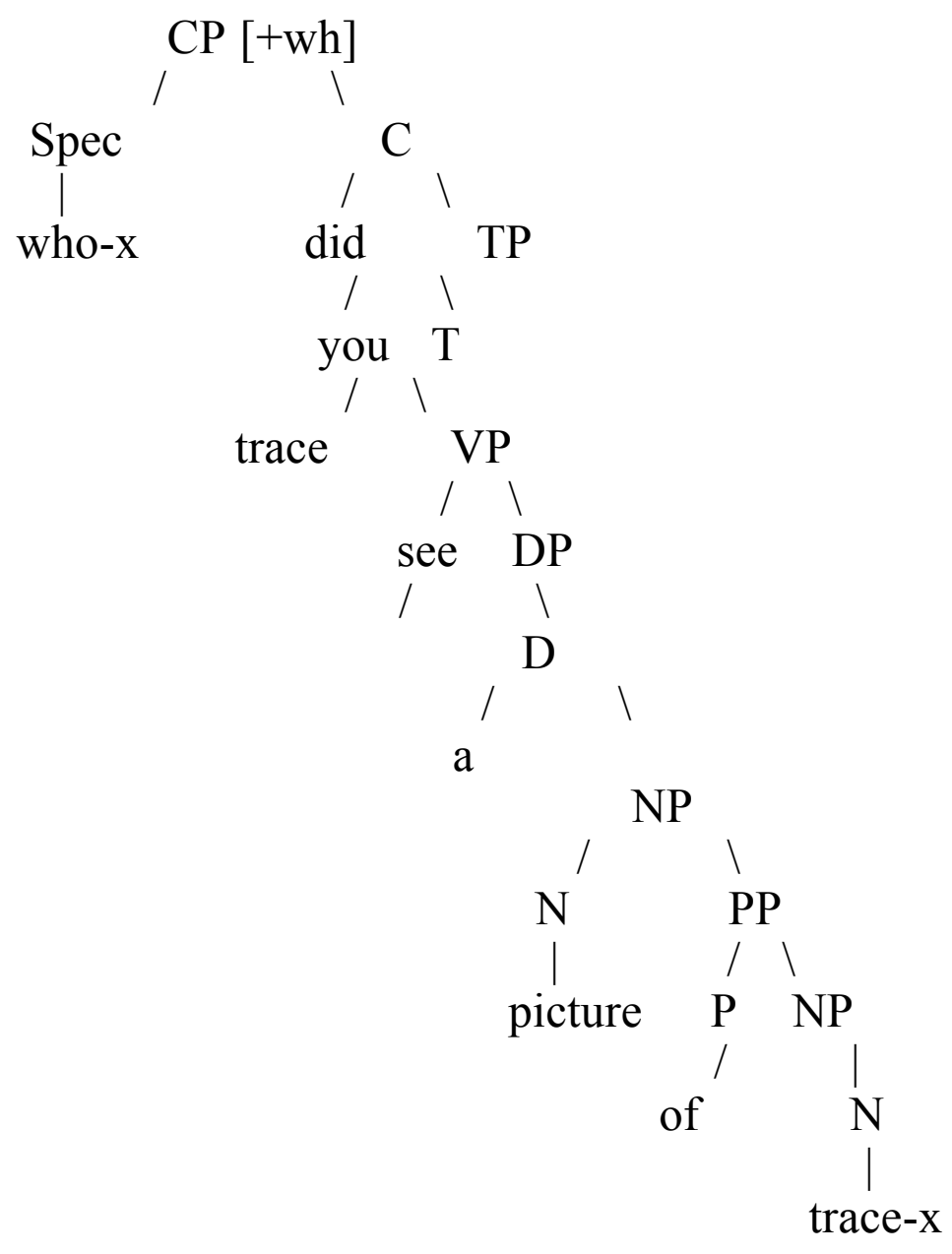

We argue that grammar should capture the notion of Seek Sublabel as a part of the economy system:

7) Economy prefers/requires minimal depth for SeekSublabel

The consequence is that we can explain the intuition of most people that a picture of whom did you see feels more complex.

Failure to satisfy a buried wh-feature can also produce a grammaticality difference. $^{7} \quad$ Pied-piping is excluded in the satisfaction of a [+wh] feature in this structure $(8 b)$ :

8) a. I wonder who you have a picture of

b. *I wonder a picture of whom you have (pc Kyle Johnson)

\footnotetext{
${ }^{7}$ Chomsky (2001) see also Roeper et al (2000) for extension of Probe-Goal to complement including PP's.
} 
Clearly the $[+$ wh] feature must be immediately satisfied, which entails rejection of any Feature depth beyond immediate domination. Now a new question arises: how can we capture the sharp grammaticality distinction in (8) while allowing a weaker "preference" in the contrast of $(4 a, b)$ ?

The notion of SeekSubel has become the subject of recent work on superiority in wh-movement, offering a variety of new formulations (Fitzpatrick (2002)). Fitzpatrick outlines several approaches, none of which captures all of the data, mirroring the contrast between (4) and (8).

The core contrast lies between Attract and Path measurement style constraints:

Attract Constituent under C-command:

Move closest constituent with relevant feature directly to

Feature-checking domain.

Path Quantification:

Choose the shortest path in the tree to satisfy a feature.

The technical statements from Fitzpatrick are:

Attract Closest C-Command:

$\mathrm{G}$ is the closest category in the sister of $\mathrm{H}$ iff there is no distinct category Ksuch that $\mathrm{K}$ c-commands $\mathrm{G}$ and $\mathrm{K}$ bears a feature matching F. ${ }^{8}$

Path Quantification:

$\mathrm{G}$ is the closest category in the sister of $\mathrm{H}$ iff there is no category $\mathrm{K}$ bearing a feature matching $\mathrm{F}$ such that the path $\mathrm{P}^{\prime}$ that would result from movement of $\mathrm{K}$ is smaller than the path $\mathrm{P}$ that would result from movement of $\mathrm{G}$.

It seems that (8a) is naturally captured by the spirit of Attract, while (4b) (and the superiority facts below) can be explained by invoking the spirit of Path. Moving a large constitutent (pictures of whom) makes a short path, but fails to Attract the minimal category (whom). We will not develop technical definitions because our goal is primarily to broaden the relevant empirical domain.

What difference is there between these constructions (4) and (8)? Note that one derives from lexical representation and how subcategorization works: wonder seeks visible immediate satisfacton of subcategorized information. Questions belong to a different domain: Illocutionary Force which is projected

\footnotetext{
${ }^{8}$ As Fitzpatrick (2002) points out, these formulations also reflect the Minimal Link Condition. See also Heck and Müller (2002) for a reformulation in terms of Phrase Impenetrability. It is not clear yet whether these formulations all make the same predictions when do-support is subjected to the same constraints. The claim here is that one should broaden the database before refining the principles.
} 
onto the $\mathrm{CP}$, and always requires movement. This provides our first clue that locality may refract differently under the prism of different modules of grammar. For instance, a Path-theoretic account would explain why (9a) is superior to (9b):

9a) who bought what

b) *what did who buy

Movement of what out a VP creates a larger distance than moving the subject who in (9a). But now if we bury the wh-, (9c) then the path measurement becomes obscure:

9c) who did some pictures of whom disturb movement from the object of disturb is not further than movement from deep within the subject phrase some pictures of whom. However if we take the Attract account, then (9b) has the same value as a phrase with no wh-word, since no buried [wh-] ever enters the computation:

9d) who did some pictures of Bill disturb

Thus Attract seems to miss a weak sense of decreasing grammaticality and Path seems to be the one to enrich to where it can explain $(9 \mathrm{c})$.

The fact that the judgments are obscure is one reason why the acquisition facts may provide a more powerful adjudicator among theories. We return to this question when we address Multiple Grammars and module-based notion of economy. First we build up relevant arguments from the verb-movement domain.

2.1 Verbal SeekSublabel/Path

We can see these principles at work where negation occurs:

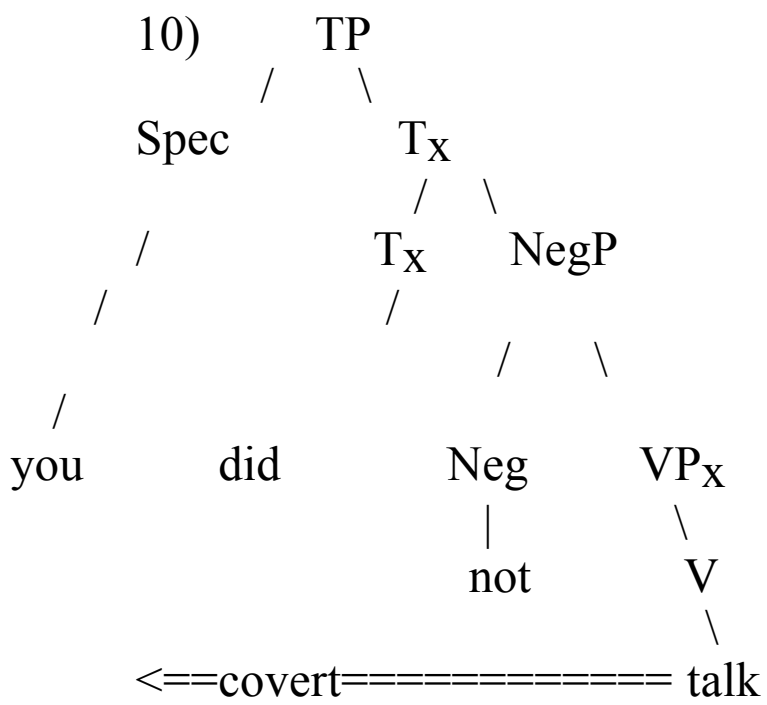

Do-insertion allows the [+past] feature to be in a Feature-command position (sister) 
with respect to the lower VP.

11a)

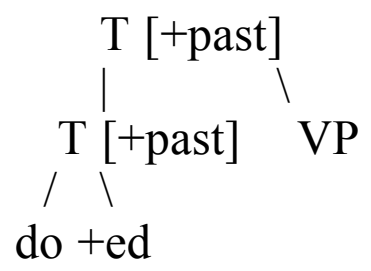

However, normal verb-movement creates a small version of the SeekSublabel/Path problem. Movement of the verb+ed requires that the Verb move, but now the [+past]-ed affix is buried one node down inside of the V. After movement, the Tense node must look inside the $\mathrm{V}$ to find [+past]:

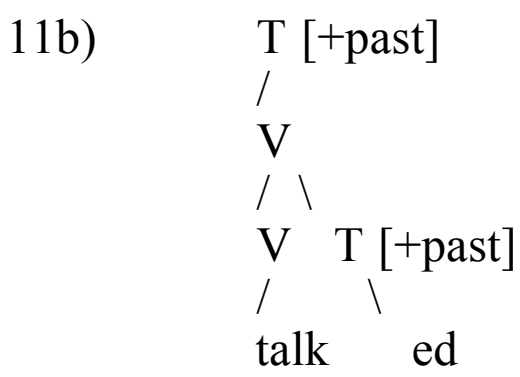

Therefore, do-insertion offers a more economic form of Feature-Checking and Feature-command, and it fits our notion of Attract directly. One should ask again why the full verb moves at all? We now need an answer to that question. ${ }^{9}$

\subsection{Acquisition Evidence for Minimal Seek Sublabel/Path}

Now we can ask: if this theory is true, then is there acquisition evidence that spontaneously honors economy, chooses immediate domination (Attract) over depth (Path) ? Hollebrandse and Roeper (1997) provide direct evidence in behalf of Immediate Domination. There are non-emphatic insertions of do in declarative sentences with no adult models. This occurs in English, Dutch, and German (see Schoenenberger and Penner (1995)):

12) a. $\quad$ "I do have juice in my cup"

"I do taste them"

"I did wear Bea's helmet"

"I did paint yellow right here. I did put the brush in.

\footnotetext{
${ }^{9}$ Lasnik (1999) provides further arguments in behalf of the view that Feature-movement should apply.
} 


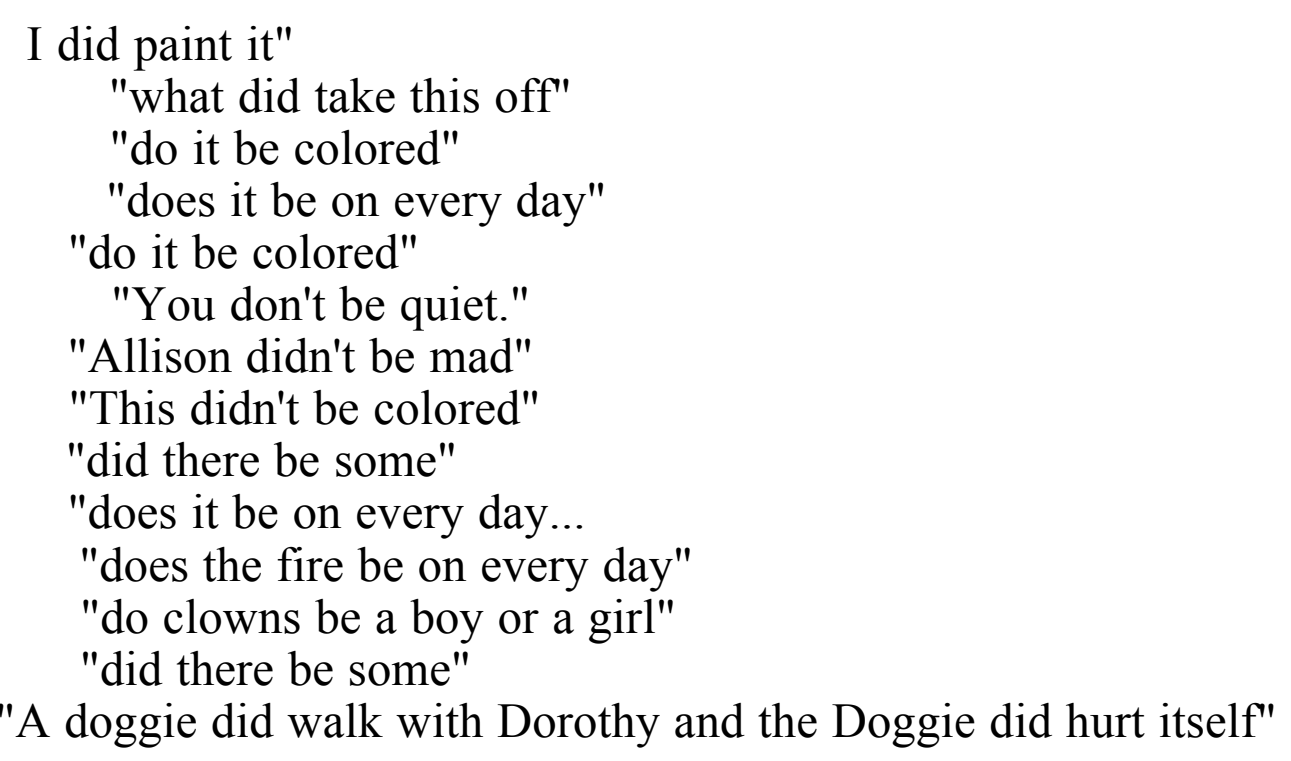

13) "ik doe ook verven" [ I do also paint] "ik does grapjes makken" [I do grapes make]

"hij doet taperecorder draaien" [he does taperecorder turn]

"wat doet 'ie bukken" [what does he stoop]

"wat doe jij zeggen" (what do you say)

"dat doe ik spelen" [that do I play]

from van Kampen (1996)

The preference for do-insertion over verb-movement suggests that the designation Last Resort is uninformative. One might more accurately say First Resort. See Schutze (2002) and Erb (in press) for a summary of a variety of dialects and contexts where this Default form predictably arises.

\subsection{Parallel Wh- Predictions}

Our initial wh- examples lead to parallel predictions. The child ought to spontaneously prefer Economic Seek Sublabel and Immediate Command. In fact, evidence from naturalistic data and experimentation over the past ten years reveals precisely this sort of phenomenon.

Hoekstra, Koster, and Roeper (1992) found both naturalistic and experimental evidence that children will break the left-branch constraint in order to honor Feature-command. Here are a few naturalistic examples:

14) "how am I big" for "how big am I"

"How is it long" for "how long is it" 
"keek eens hou ik groot ben"

[look how I big am]

In addition, Guasavara and Thornton (2001) found numerous examples of children extracting just a wh-word from a leftbranch in both naturalisrtic and experimental data:

15) "who did you see's book"

The fact that these forms of economy appear to overrule whatever generally enforces the Leftbranch constraint and favors Pied-piping remains an interesting challenge from acquisition evidence for linguistic theory. It suggests that Piedpiping larger chunks invokes the principles that allow Path computation for whexpressions, but the acquisition mechanism initially prefers Attract. (See Koster (2000a) for arguments that amounts of Pied-piping is a domain for cross-linguistic parametric variation. ${ }^{10}$ ) Therefore we find that our basic approach receives support from several quarters.

3.0 AGR and Negation: what forces deletion?

A variety of theories have been put forward for the persistent fact that children may delete Agreement or Tense nodes in the course of acquisition ("he play" for "he plays".). One strain argues that children have a weaker Checking requirement. For instance, Schütze and Wexler (1996) argue that children must satisfy either Tense or Agreement. Owen and Benedicto (2001) make a more refined argument in on behalf of the view that children may satisfy just one Phifeature. Roeper and Rohrbacher $(1994,2000)$ argue that UG options play a role: children may have a Default grammar in which there is no Feature-checking requirement for Tense/Agreement. In effect, they choose an Asian grammar, which by hypothesis, does not require this node (Speas (1994)). That account explains the presence of a number of examples like "where go" (but never *where goes) in early files and the fact that subject deletion co-occurs with Tense deletion.

Schütze (2001) has done a close analysis of the naturalistic data and discovered that much of the deletion is sensitive to negation. He points out that

\footnotetext{
${ }^{10}$ Guasti and Cardinaletti (to appear) point to a variety of differences for Pied-piping with questions and relative clauses (which correlate with resumptives as well). In particular they point to Pied-piping in questions and non-Pied-piping in child relatives. If the conditions on how relatives are adjoined (a kind of weak subcategorization) involve a different kind of Feature-checking locality, as we saw with wonder, then it may not be surprising that sharper locality restrictions are imposed on relative clause wh- feature-checking than on interrogative feature-checking. As they suggest, this is just the kind of variation a Multiple Grammars approach would allow.
} 
there are numerous instances of missing AGR/Tense with negation, but virtually none without. For instance, statistics on Nina and Sarah show:

16)a. Nina: "he do" 1/ "he don't" 65
Sarah: $\quad 34 /$

Schütze argues that do attaches to stray affixes that require a root in order to appear. Unless the affix is phonologically real, the do does not get inserted. Those instances where the AGR feature is not represented by any phonological information, a null affix, requires no do-support and therefore children will say: b. he play ${ }^{11}$

Now, however, we may ask whether these facts will submit to the analysis we have just advanced. In other words, does an economy factor conspire to promote deletion when do attaches to negation? A structural reason for AGR/Tense omission would not make it a random occurrence. In fact, as Guasti/Rizzi argue, AGR/TNS deletion is far from random. Their evidence poses another challenge which we consider below.

The notion of cliticization is precisely to create a more complex object with greater internal structure. We argue that however one chooses to represent this fact, the presence of a Negative Clitic forces the AGR affix to a lower position in a tree:

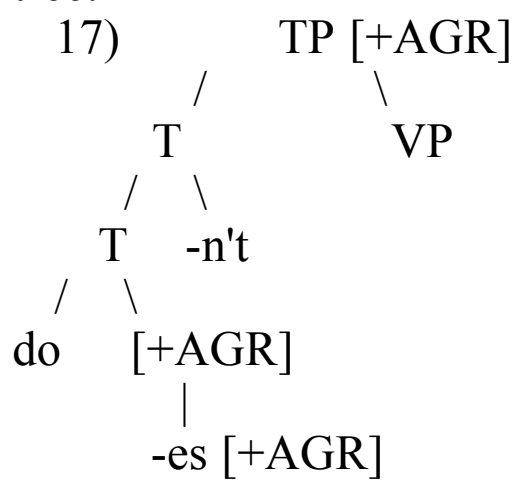

Precisely as we argued for buried [+past] in walked, the -es is now buried by virtue of the cliticized negative. Therefore if Checking must occur, then it must reach down below the cliticized Neg. Therefore we argue: if Seek Sublabel/Path is indirect, then choose an economical Default, which may avoid the computation altogether,namely Attract. If Attract cannot be satisfied, then deletion of [-es $=$ AGR $]$ is the only option to allow the derivation to succeed.

The most economical default is precisely the Asian option where there is no AGR to be satisfied. Note that this solution requires that Feature-checking occurs

${ }^{11}$ It is not clear under this explanation why there are 34 instances of "he do" for Sarah. 
after cliticization. One variant of this approach would be to argue that in fact cliticization should occur after lexical insertion under Distributed Morphology (Halle and Marantz (1993)). This analysis, however, depends upon putting the AGR within the TP and not an independent node. That is, if we had two nodes, under the Guasti/Rizzi model, then it would be:

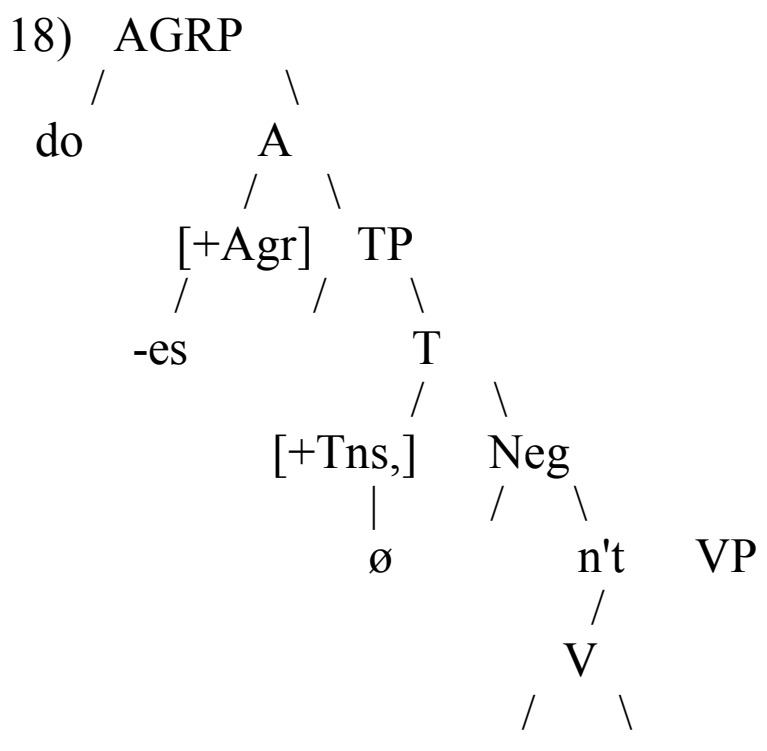

In this system, the -es is not lower and therefore no reason exists for it to undergo deletion. Instead there is a separate raising operation for Neg, Tns, and AGR.

Therefore our analysis provides direct acquisition support for Chomsky's claim - based on interpretability - that TP should subsume an AGR feature rather than projecting an independent node. Putting AGR lower makes the Path deeper, which blocks immediate Feature-checking.

\subsection{Specific Langauge Impairment [SLI]}

Roeper et al (2000) provides a similar argument from SLI grammars for the treatment of AGR as a Feature of TP rather than a separate node, namely, correlations between verbal ("Me don't know") nominal ("me Daddy"), and prepositional deletion ("Me go beach not far away" ) varieties of Agreement all of which show a simultaneous deficit in a child who otherwise shows the capacity for wh- movement ("That why them put a lot of sand in"), quantification and raising over Neg ("Me never take a shower"), and reflexivization ("her standing and her see herself"). It appears that other modules advance substantially where no Agreement is involved. 


\subsection{The Inversion Challenge}

This analysis must confront the facts uncovered by Guasti/Rizzi. They show that the presence of AGR is far more likely under inversion. Their tabulations are:

\section{Do Does}

$$
\begin{array}{lrl}
\text { NEG } 144 & 220 \\
\text { INT } & 5 & 270 \\
X^{2}=128.29 & p<0.005
\end{array}
$$

[ Do vs. does in negative and interrogative sentences for the 5 children investigated]

This result clearly shows that Agreement is much more likely in the case of inversion.

Our analysis has no straightforward way to account for these facts. Their analysis has no straightforward way to account for the impact of negation on the presence of AGR. In order to preserve our analysis, then, another account for why AGR is present in inversion must be found. We make a tentative proposal here, although any analysis that would allow AGR to be buried in Tense would accomplish the same goal.

Suppose we simply argue that Subject-Auxiliary inversion is in reality:

20) Subject-Agreement inversion

This would assert that an AGR feature must be involved, but not assert that it must be an independent node. It is a requirement on the Feature content of the moved entity. As such it would require Feature-Checking in the new environment. It would be AGR+yes/no that motivates movement.

\section{1) Subject inverts with AGR+yes/no}

If this Feature bundle moved, then it would prefer Minimal Seek Sublabel/Attract as well.

In fact, there is evidence reported by Roeper (1992) and Guasti, Thornton, and Wexler (1993) to this effect. We find for instance:

21) a. "do you don't want to go outside too?" (Roeper (1992)

b. "What did he didn't want to bring to school" Preference found for 10 children 
(Guasti,Thornton, and Wexler (1993) $^{12}$

Why does the full negative auxiliary fail to move? Our account suggests that Attract prefers immediate satisfaction to Feature-checking under Seek Sublabel/Path.

At an earlier stage, we find auxiliary copying, but it is clearly promoted by the presence of the negative ("did I didn't"). If we assume that a yes/no feature exists in the CP, then it is minimally satisfied by AGR:

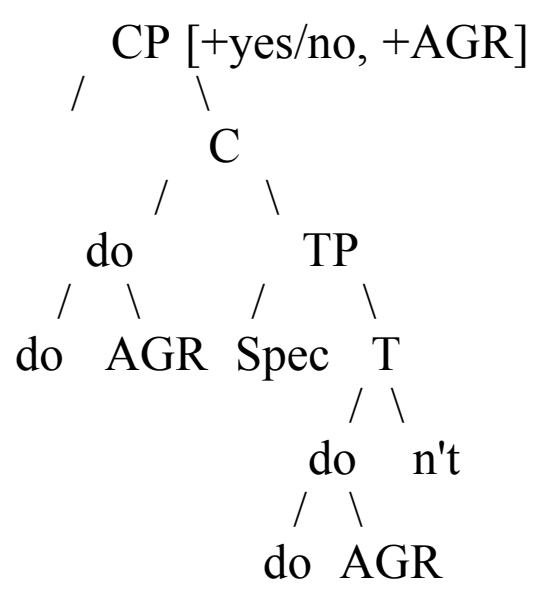

The AGR+yes/no Feature bundle can also explain the presence of bare do under inversion. Some Feature beyond AGR must force inversion in the creation of yes/no questions. This approach also can allow the Schütze account to cover cases of bare inverted do:

23) "do it be colored"

Children readily prepose do to form yes/no questions. We find a number of them in the examples above. If inverted do carries a more complex Feature bundle, then it would be used to support more than AGR. This then would require a revision in Schütze's account to state that inversion makes a Feature syntactically visible if not phonologically visible, and that movement is sufficient to force doinsertion $^{13}$.

Inversion in wh-questions reveals the same pattern. One of the earliest

\footnotetext{
${ }^{12}$ An anonymous reviewer suggests that "n't" cliticization could be a PF operation. A very nice study of partial movement and negation in English (Abdulkarim (2001)) shows that "n't" blocks LF movement, but not "not". This result entails that cliticization requires a pre-existing Head and must occur in the syntax.

${ }^{13}$ Schütze (2002) provides evidence of "does" and not "do" in non-inverted environments like "Mark does too" which is predictable under our Path account, but not by Guasti/Rizzi. In addition, he provides evidence that a subtle form of Mood marking may be involved where do is inserted.
} 
observations about wh-questions is that children resist inversion with negation (Klima and Bellugi (1966)). This was initially explained in terms of number of transformations. In effect, we translate that account into one of tree depth.

Recently, Rowland and Pine (2000) provide extensive evidence that children prefer to invert precisely those forms that involve Minimal Seek Sublabel (does, did) and also (is, was). The latter have been argued by Lasnik to be directly inserted under Tense, rather than moving from a lower V-position. This leads to precisely the prediction that a grammar that prefers Minimal Seek Sublabel /Attract will be inverted first by children.

24) Auxiliairies inverted (for Adam)

Inverted/Non-inverted

Tensed 111/118 (did, does, was, is, has, had)

Modals 5/32

Negative $0 / 26$

Questions with Modals and Negatives, each involving SeekSublabel/Path are clearly avoided initially.. They argue that it is because the modal lacks overt Tense. In our system, the raising of the Modal to the Spec of TP will have the impact of lowering the (invisible) Tense feature in the tree, thereby making Minimal Seek Sublabel /Path more difficult.

In sum, we have proposed an avenue to meet the challenge posed by Guast/Rizzi analysis. In essence, while their astute observation demonstrates the role of Agreement in inversion, it does not necessarily hinge upon the tree-structure that they advocate.

\subsection{Tense/AGR Predictions}

The theory of Schütze and Wexler (ATOM) seeks to account for the possibility 'that either Tense or Agreement is deleted. That possibility is compatable with the Seek Sublabel /Path Economy approach. However, we are able to make a further prediction: Agreement, if lower in the tree, should delete more readily than Tense when negation occurs. This prediction is difficult to evaluate statistically at this point, but it may be relevant as our data becomes more refined. (See Schütze (2002) whose evidence on this point suggests that Tense deletion is harder to find than Agreement-deletion. However the argument depends upon situational estimates of where past tense should occur.)

We also have a prediction about German which should be possible to evaluate. If it is the case, as argued by Zwart (1993), that subject-verb-object in Dutch is an IP structure, with no V-2, but object verb-subject is true V-2 in CP, then we make a prediction to the effect that AGR should be present more readily when the object is preposed, than when the subject is first. On the other hand, if 
AGR is equally present in the two cases, then it argues on behalf of the V-2 everywhere view. Future work should reveal the answer.

\subsection{Economy and Multiple Grammars}

We have utilized an economic notion---Attract- to account for the preference for (26a) and the notion of SeekSublabel/Path to account for the grammaticality of (26b).

26) a. who did you want a pictured of

b. a picture of whom did you want

Why should locality not choose one form? We have argued that the Lexical subcategorization properties are in a different module from wh- Movement. Satisfaction of subcategorization can therefore require an additional property--equivalent to the old notion of Proper Government (=immediate domination) which presents a different range of factors to be satisfied by movement operations than those found in other forms of Feature-checking linked to Functional Categories. Therefore the competing constraints identified by Fitzpatrick may be independently needed when independent demands of various modules are honored.

The same question can be asked about verb-raising itself: why should some grammars raise the verb overtly and others raise the verb covertly? We will sketch an approach to these questions that exploits the modularity of grammar.

We propose that economic factors should be relativized to different modules:

27) Economy should be measured independently in each module (see Roeper (1999))

This is a natural consequence of the fact that the primitives in each module (case, thematic roles, chains) are different. Therefore one concept of simplicity (e.g. economy) cannot fit them uniformly. It is natural therefore that simplicity in one module generates complexity in another. This abstract point deserves some emphasis: We are asserting that it is inherently in the nature of biological objects whose parts contain smaller "organs" that one system of simplicity cannot apply across the whole system. This perspective has non-trivial consequences, but this is not the place to explore them at the abstract level. Instead we will proceed with this perspective as a guiding concept and see how it leads to a theory of Multiple Grammars.

What other module is subject to the impact of syntactic variation.? We argue that semantic economy is affected by syntactic chocies, although it may itself contain subdomains (thematic roles, quantification). In a word, we propose that 
every shift in syntactic structure alters the micro-scopic semantics associated with it. The consequence is that syntactic simplicity can generate semantic complexity. It is important to observe the impact of the term microscopic: microscopic changes are those that have no impact in the bulk of sentences. We provide two examples and leave this notion as a suggestion.

\subsection{The Semantics of Verb-Raising ${ }^{14}$}

It is often asserted that overt verb-raising has no semantic consequences. But it can hardly be an accident that in English the verb does not raise and that it has a generic reading that is not anchored in the present for sentences like:

\section{8) John plays tennis}

The generic interpretation of (28) has led people to say commonly that "English has no present tense".

What it actually lacks is a temporal-anchor: a situation link that is like a definite article which confers time-specificity, which we will illustrate in a moment. Some subtle (microscopic) examples are needed to grasp exactly what we mean. Moreover, this concept no doubt needs a careful articulation in light of concepts of aspect, sequence of tense, and other semantic factors. However we think an intuitive version provides an adequate link to the syntax.

We claim:

29) Overt verb-raising provides a Tense-anchor that does not occur when raising is Covert.

The raised verb in German supposedly captures both the generic reading and the progressive reading. A close look, however, shows that the Present tense is available, but not the progressive. In English one can say:

30) John is killing Bill, but he should stop

but not:

31) ). *John kills Bill, but he should stop

in other words, the present tense carries a [+telic] reading that prevents the added phrase "but he should stop". The German translation of (31) has present tense force, but it is also ungrammatical:

${ }^{14}$ See S.. Zuckerman (2001) Groningen for an argument that optionality has motivation and for evidence that do-insertion has a meaning effect. 
32) *Er tötet Fritz, aber er soll aufhören

Stage directions in English carry the [+telic] reading:

33) King kills slave $=/=$ king is killing slave]

*king kills slave, but suddenly stops

The raised verb therefore captures a slightly different kind of present than the be+progressive circumlocution used in English.

In effect, then, there is a missing meaning in English: present telic verb. And in German there is no direct progressive in the verb system. The meaning is achieved by a nominalization:

34) Fritz ist am Töten/ Fritz ist beim Töten. .

We arrive at the familiar observation that different grammars express the same meanings in slightly different ways. However, there is a stronger consequence from this argument:

35) Overt Feature-checking entails meaning shifts not found in Covert Feature-checking. ${ }^{15}$

Recent work by Sauerland and Elbourne (2002) makes a similar suggestion about covert subject-verb Agreement. They point out that (shifting to American English examples, since these are acceptable in British English), one can say (36a) but not (36b):

36) a. a group of men are here

b. *there are a group of men here

c. British: the committee are here

d.* there are the committee here

They argue, in effect, that certain forms of subject-verb agreement are fixed at PF and therefore unable to undergo Covert movement and retain a lower interpretation. We argue that certain forms of anchoring, still just intuitively identified, require overt movement as well. Since this is not the primary topic of this paper, we leave this as a suggestion. which calls for a more precise investigation.

\subsection{Syntactic and Semantic Complexity}

\footnotetext{
${ }^{15}$ If one suggests that Covert-movement is not required, then the claim is simply that Overt-movement is required to anchor certain temporal effects.
} 
involved:

Our general argument, at an intuitive level, is that two kinds of simplicity are

37) Verb-raising

a. semantic simplicity: raise the verb $=>$ direct present tense telic

b. syntactic complexity: Seek Sublabel/Path is indirect because the morphology must be found inside a V-projection

Alternatively, if there is syntactic simplicity, then there is semantic obscurity:

38) Do-insertion:

a. syntactic simplicity: do-insertion, no verb-raising overtly

b. semantic complexity: indirect representation of present tense, no telicity involved.

This proposal invites the development of a semantic model in which an economy metric can be stated. So far we have just said that if one must combine two verbs to generate the notion "present", then there seems to be a kind of semantic complexity present that is not required if one generates the present directly by movement. This is just an example and not a model.

Note that it is very rare that the semantic distinctions which arise make a difference. In most situations:

\section{9) John is playing baseball}

would not have to have an implied telic result and therefore would mean the same as the raised German form: Er spielt Fussball. It is only in special environments that one can tease out a semantic difference. Nevertheless, it is microscopic differences which provide scientific insights and therefore they can be of great intellectual significance even if they are of very little communicative significance.

Ultimately, a single "grammar" may favor either syntactic or semantic simplicity in different modules, or even in different lexical verb-classes. In effect, two kinds of "grammar" are involved and therefore in a sense, every speaker is a speaker of Multiple Grammars, if particular modules make particular choices. (See Roeper (1999) for an argument that quotation "yes" said Bill involves Germanic V-2.) We put the term grammar in quotation because as our level of magnification increases, the term begins to lose its basic coherence. We might advance to a notion of modular simplicity.

\subsection{Pied-Piping and Scope}

If this approach to syntactic/semantic variation is correct, then we predict that there should be a distinction between: 
40) a. a picture of whom do you want to see

b. who do you want to see a picture of

We argue that (40a) favors the wide-scope reading of "a picture" and (40b) favors the narrow scope reading. It is a particular picture that one wants to see.

Therefore we now have a reason why strict Attract is not always obeyed for whmovement.

These preferences are like the familiar ones with passive:

41) a. everyone in the room speaks two languages

b. two languages are spoken by everyone in the room

In (41b) the wide scope (same two languages) is favored, but reconstruction is possible. Here we need to refine the notion of grammaticality judgement. Our system leads to the possibility that we sense a difference, a preference, for different readings in each case. The wide-scope reading for (40a) is more natural, a specific picture is involved, because it is semantically simple (Surface Structure $=$ LF), while a narrow scope reading of (40b) is natural with "a picture" inside the VP. Now we can construct a more complex metric:

42) simple syntax + narrow scope $=>$ ideal for $(40 \mathrm{~b})$

simple syntax + wide scope $=>$ one LF movement, more complex

complex syntax + wide scope $=(40 a)$ no $L F$ movement complex syntax + narrow scope $=$ reconstruct "a picture", more complex

The judgment of grammatical or ungrammatical is too crude to state this range of possibilities, but they are what arises if we imagine that different forms of simplicity in different modules are in conflict. What one can feel is an appropriate sense that the computational systems are distinct here. If one can factor in both systems, then we arrive at the view that the narrow scope reading of (40a) is the most difficult, and perhaps earns a ? judgement, while the narrow scope reading of (40b) involves both syntactic and semantic simplicity and therefore should be the easiest. The other two possibilities lie in between. ${ }^{16}$ Other factors, like speech register, could also have an influence on the choice. For instance, to whom did you speak feels more formal than who did you speak to. Chomsky (1987) in fact suggested that pro-drop phenomena may be linked to speechregisters. Our proposal supports that conjecture by suggesting that grammar-shift would be a natural signal of speech-register shift.

${ }^{16}$ This approach (see Roeper (1999)) is compatible with the proposals in Sauerland and Elbourne (2002) and Fox (1995) where the possibility of movement is linked to whether an interpretive difference arises. 
6.0 Conclusion

We have argued on behalf of:

A) the role of acquisition data in identifying and justifying fundamental operations in UG.

In addition, we have made a proposal that

B) refines the formulation of Feature-checking to include a metric that measures the complexity of Seek Sublabel/Path.

We have argued that if economy is interpreted in terms of a variety of modules,

C) then there may be no uniform simplicity across a grammar.

The preferences found in individual modules are typical for certain grammar types. A V-2 grammar maximizes semantic simplicity, but creates syntactic complexity. A do-insertion grammar maximizes syntactic simplicity, but creates semantic complexity. Particular languages will exhibit different preferences for different modules, different speech registers, and different lexical classes. In that respect, every language contains Multiple Grammars (Roeper (1999), Yang (2001).

Bibliography

Abdulkarim, L. (2001) Complex Wh-Questions and Universal Grammar:

New Evidence from the Acquisition of Barriers Umass. Dissertation

Bobalijk, J. (1995) Morphosyntax: the syntax of verbal Inflection

MIT Diss.

Chomsky, N.(1987) Knowledge of Language (Praeger)

Chomsky (1995) The Minimalist Program (MIT Press)

Chomsky (2001). "Beyond Explanatory Adequacy" MIT ms.

Chomsky (2000) "Derivation by Phase" in Ken Hale: A Life iin

Linguistics ed. M. Kenstowicz 1-52 (MIT Press)

Drenhaus, H. (2000) "From head to adjunct:: Evidence from the acquisition

of German ditransitive verbs" eds.S.C. Howell, S.A. Fish, and T. Keith

Lucas BU 24 Cascadilla Press

Erb, C. (2001) Finite Auxiliaries in German Ph.D. Tilburg Universiteit

Fitzpatrick, J. (2002) "On Minimalist Approaches to the Locality of

Movement" LI 33.3 443-463

Fox, Danny (1995) Economy and Semantic Interpretation LIMonographs 35

MIT Press 
Guasti, M. and A. Cardinaletti (to appear) "Relative Clause Formation in Romance Child Production" Probus

Guasti, M. and L. Rizzi (2002) "Agreement and Tense as Distinct Positions: Evidence from Acquisition" in G. Cinque ed. The Cartography of syntactic Structures Oxford University Press

Guasti, Thornton, and Wexler (1995) "Negation in children's questions: the Case of English" In D. MacLaughlin and S. MacSwan eds.BUCLD 19

Guasavara, E. and R. Thornton (2001) "Getting it Right" Language Acquisition Vol. 9, No. 3

Halle, M. and A. Marantz (1993) "Distributed Morphology" in SjKeyser The View from Building 20

Heck, F. and G. Müller (2002) "Repair-drivern Movement and the Local Optimization of Derivations "(2002) Ms. University of Tübingen

Hoekstra, T. and P. Jordens (1992) "From Adjunct to Head" InLanguage Acquisition and Language Disorders T. Hoekstra and B. Schwartz 119-149 Amsterdam

Hoekstra, Koster, and Roeper (1992) "Acquisition of the LeftBranch Condition" BU presentation

Hyams, N. (1996) "The Underspecification of functional categories in early grammar" in $\mathrm{H}$. Clahsen ed. Generative Perspectives on Language Acquisition Benjamins

Holledbrandse,B. and T. Roeper (1995) "The Concept of Do-insertion and the Theory of INFL in Acquisition" in C.Koster and F.Wynen Groningen Assembly on Language AcHquisition

Klima, E. \& U. Bellugi (1966) "Syntactic Regularities in the Speech of Children". J. Lyons \& R. Wales (eds.) Psycholinguistic Papers. Edinburgh University Press 183-207.

Koster,J. ((2000a) Pied Piping and The Word Orders of English and Dutch. NELS 30

Kroch,A. and A. Taylor (1997) "Verb Movement in Old and Middle English: dialect variation and Language Contact" in van Kemenade, A. and N. Vincent (eds.) Parameters of Morphosyntactic Change Cambridge University Press

Lasnik, H. (1999) On feature strength: Three minimalist approaches to overt movement. Linguistic Inquiry 30:197-217. 
Lebeaux, D.(2000) Language acquisition and the form of the grammar.

Phd Dissertation, Benjamins,

Müller, G. (2002) Düsseldorf Summer School Handouts

Müller,N. and A. Hulk (2001) Crosslinguistic Influence in Bilingual Language Acquisition: Italian and French as Recipient Languages* Bilingualism: Language and Cognition

Owen, A. and E. Benedicto (2001) "Processing Effects and Use of Nondistinct Features in SLI: An Error Analysis of Verb Morphology" Purdue ms. Linguistics Dept.

Perez,.A., A. Munn, and C. Schmidt (in preparation) "Acquisition of Generics" Lingiustics Dept ms. University of Toronto

Powers, S. (1996) The Growth of th4e Phrase-marker: Evidence from Subjects University of Maryland Diss.

Roeper, T. (1992) From the Initial State to V-2: The Architecture of Acquisition in J. Meisel The Acquisition of Verb Placement

Roeper (1996) "The Role of Merger and Formal Features in Language Acquisition" in H. Clahsen Generative Studies of Case and Agreement (John Benjamins)

Roeper, T. (1999) "Universal Bilingualism" in Bilingualism 2.3

Roeper,T. and B.Rohrbacher (2000) "Null subjects in Early Child English and the theory of Economy of Projection" in eds. C. Haaman and S. Powers Proceedings of the Conference on Acquisition of Scrambling andthe Middle Field (Kluwer)

Roeper, T. with Eliane Ramos, Harry Seymour, Lamya Abdul-karim (2000) "Language Disorders as a Window on Universal Grammar:

An Abstract theory of Agreement for IP,DP and V-PP" Brain and Language

Rowland, C. F. \& Pine, J. M. (2000). Subject-auxiliary inversion errors and wh-question acquisition: What children do know? Journal of Child Language, 27, 157-181.

Satterfield, T. (2000 ) Bilingujal Selection of Syntactic Knowledge Kluwer

Sauerland, U. and P. Elbourne (2002) "Total Reconstruction, PF Movement, and Derivational Order" LI Vol 38.2, J.

Schönenberger,, M. and Z. Penner (1995) "Probing Swiss German Clause by Means of the Placement of Verbal Expletives: Tun "do" insertion and verb-doubling" Topics in Swiss German Syntax (Peter Lang)

Schütze, K. and K. Wexler (1996) "Subject Case Licensing and English Root Infinitives" BUCLD eds. A. Stringfellow, D. Cahana-Amitay, E. Hughes and A. Zukowski Cascadia Press

Schütze (2002) "Some Do's and don'ts in Child and Adult Grammar" Umass, Handout 
Speas, M. (1994) "Null Arguments in A Theory of Economy of Projection". University of Massachusetts Occasional Papers in Linguistics 17

Tracey, R.(1991) Sprachliche Strukturentwicklung Narr van Kampen (1996)"PF/LF Convergence in Acquisition NELS 26

Yang, C. (2000) Knowledge and Learning in Natural Language MIT Dissertation

Zwart, J-W (1993) Dutch Syntax: A minimalist Approach Groningen Dissertation

Zuckerman, S. (2001) The Acquisition of "Optional" Movement Groningen Dissertation 